\title{
Effect of Fuel Cetane Numbers on Reducing the Ignition Delay Period and Exhaust Emissions from DI Diesel Engine
}

\author{
MAHMOUD MOHAMED EL-GHOBASHY EL-HAGAR \\ Mechanical Engineering Department \\ Industrial Education College \\ Beni-Suef University \\ EGYPT
}

\begin{abstract}
In this present study a theoretical investigation is used to examine the effect of different fuel cetane numbers $(C N s)$ on reducing the ignition delay and exhaust emissions from diesel engine at certain operating conditions. The operating conditions for such diesel engine include compression ratios, engine speeds and intake pressures and temperatures. For this purpose, the fuels with 40 and $50 \mathrm{CN}$ were tested in a four cycle, four cylinders direct injection $(D I)$ diesel engine. Theoretical analyses were conducted for the standard injection pressures $(150 \mathrm{bars})$; the exhaust emissions were tested at engine speeds from $4500 \mathrm{~min}^{-1}$ to $1000 \mathrm{~min}^{-1}$ at full engine load. The results showed that, at all operating conditions, the ignition delay decreases as the cetane number, compression ratio, engine speed, intake pressure and temperature are increased so that combustion efficiency is improved. Also the exhaust emissions $\mathrm{NO}_{X}, \mathrm{SO}_{2}$ and $\mathrm{CO}$ are reduced when the fuel $\mathrm{CN}$ is increased from 40 to 50 for the standard injection pressure $(150$ bars $)$. Increases in engine torque and power output were observed when the $C N$ is increased.
\end{abstract}

Keywords: - Diesel engine, Injection pressure, Engine speed, Cetane number; Compression ratio; Intake pressure and temperature, Ignition delay period, Exhaust emissions, Engine performance

Received: November 20, 2019. Revised: May 8, 2020. Accepted: May 30, 2020. Published: June 16, 2020.

\section{Introduction}

Combustion in a Diesel engine is a complicated physical and chemical process, starting with the fuel injection into the combustion chamber to exhausting the burnt gases. The reason for the complication is that the combustion depends on many different parameters, such as mixing of airfuel, injection pressure and time $[1,2]$. Fuel vaporization itself is also a complex process because, of the fuel contents, the self-ignition of the fuel vapor is directly related to the chemical process in the combustion chamber [3].

The efficiency of a Diesel engine depends upon the conversion rate of the chemical energy of the fuel into heat releases. This speed of heat release depends on the amount of fuel injected, ignition at an adequate time and the combustion process $[1,4]$.

Diesel engine performance, combustion efficiency and emissions are simply related to the engine design and running parameters and fuel properties $[5,6]$. These parameters are important for optimization of the engine performance and for reducing emissions. The Diesel fuel chemical contents and characteristics govern the emissions and power-torque characteristics.
One of the reasons for forming exhaust pollutants is insufficient combustion in the engine cylinder. Fuels properties also play a significant role to increase or decrease exhaust pollutants. Various investigations clearly reported that cetane number $(C N)$ affects exhaust emissions [7-9].

Hydrocarbon contents in diesel fuel affect the combustion process. Fuel cetane number is increased by the parafinic hydrocarbons in the fuel. The ignition delay period is reduced by increasing the cetane number and this allows the stable running of the engine $[10,11]$. The cetane number also affects the combustion efficiency and this ensures the engine can be started easily. However, if the cetane number is excessively higher than the normal cetane number of 46 then the ignition delay will be too short to spread the fuel into the combustion chamber. As a result of this shorter ignition delay and the normal cetane number of 46 , the engine performance and smoke value will increase [12]. In the case of a lower cetane number, knocking occurs in the engine. The cetane number affects exhaust emissions. The NOx emissions decreases when the cetane number is increased [13]. 
The physical properties of the fuel such as viscosity, volatility and flash point also affect the combustion process. The viscosity affects the pulverization and vaporization of the fuel and the volatility ensures good mixing of the fuel with air. In order to increase the cetane number some additives (e.g., aniline nitrate) can be used to reduce the ignition delay $[12,13]$.

In this theoretical study, the effect of different fuel cetane numbers $(\mathrm{CNS})$ on ignition delay period and exhaust emissions from diesel engine has been investigated. Cetane Numbers of 40 and 50 of the fuels have been chosen to investigate its effect on combustion characteristics and exhaust emissions.

\section{Emission Formations in Diesel Engines}

Exhaust emissions are the Achilles' heel of diesel engines. Diesel exhaust tends to be high in $N O x$ and particulates, both visible (smoke) and invisible. Both $N O x$ and particulates are significant environmental pollutants.

Unlike the exhaust of gasoline engines, diesel exhaust contains much less unburned or partially burned hydrocarbons and carbon monoxide. Because of the importance of diesel emissions, it is worth while taking a closer look at the combustion process to see how they are formed.

Since the physical and chemical processes taking place in a cylinder during combustion are very complex and not completely understood, this discussion is necessarily superficial.

As fuel is injected into a cylinder under high pressure, it atomizes into small droplets and begins to evaporate as it moves away from the nozzle.

The fuel-air ratio at any point in the cylinder may range from zero, at a point with no fuel, to infinity, inside a fuel droplet that has not yet vaporized. In general, the fuel-air ratio is high near the nozzle tip and low away from it, but because of the complexity of the mixing process, the fuel-air ratio does not change uniformly within the cylinder. Combustion can only occur within a certain range of the fuel-air ratio; if the ratio is too low, there is not enough fuel to support combustion, and if the ratio is too high, there is not enough air.

As the fuel vaporizes into the hot air, it starts to oxidize. As more fuel vaporizes and mixes with air, the number and rate of the oxidation reactions increase until the end of the ignition delay period, when ignition occurs at many locations independently and combustion propagates very rapidly in regions which have fuel-air ratios in the combustible range. This initial combustion after ignition is called the pre-mixed combustion phase; it consumes only about $5 \%$ to $10 \%$ of the fuel used by the engine at typical full-load operation.
At the end of the pre-mixed combustion phase, most of the fuel has yet to be injected or is still in a region that is too rich to burn. But injection continues and fuel continues to vaporize and mix with air, aided by the heat release and turbulence generated by the initial combustion. This quickly generates more gas with the required fuel-air ratio and combustion continues. This is called the diffusion controlled or mixing controlled phase of combustion and, ideally, consumes all of the remaining fuel.

With this background, we can better understand how pollutants are formed during combustion in a diesel engine. NOx, hydrocarbons, $\mathrm{CO}$, and particulates are all formed under different conditions and via different mechanisms.

\subsection{Nitrogen Oxides}

$\mathrm{NO}$ and $\mathrm{NO}_{2}$ tend to be formed in the stoichiometric and slightly lean regions where there is excess oxygen and the temperature is high. Outside of these regions, either there is insufficient oxygen to form NOx or temperatures are too low for the reactions to occur quickly enough.

\subsection{Hydrocarbons}

$H C$ emissions can be either unburned or partially burned fuel molecules, and can come from several sources. At ignition, some of the vaporized fuel will already be in a region that is too lean for it to burn; and unless it burns later in the cycle, this fuel will be emitted. The cylinder walls and "crevice" regions around the top of the piston edge and above the rings are much cooler than the combustion gases and tend to quench flames as they encroach. Thus, fuel at the cylinder wall can contribute to $H C$ emissions. Fuel that does not vaporize during a cold start makes up the white smoke seen under this condition. A small amount of fuel can also dissolve in the thin film of lubricating oil on the cylinder wall, be desorbed in the expansion stroke, and then emitted. However, since diesel engines operate at an overall lean fuel-air ratio, they tend to emit low levels of hydrocarbons.

\subsection{Carbon Monoxide}

$C O$ is a result of incomplete combustion and is formed mostly in those regions of the cylinder that are too fuel-rich to support complete combustion, although it may also originate at the lean limit of combustible fuel-air mixtures. If temperatures are high enough, the $C O$ can further react with oxygen to form $\mathrm{CO}_{2}$. Because diesel engines have excess oxygen, $C O$ emissions are generally low.

\subsection{Particulates}

Some of the fuel droplets may never vaporize, and thus, never burn. But the fuel doesn't remain unchanged; the high temperatures in the cylinder cause it to decompose. Later, these droplets may be 
partly or completely burned in the turbulent flame. If they are not completely burned, they will be emitted as droplets of heavy liquid or particles of carbonaceous material.

The conversion of fuel to particulates is most likely to occur when the last bit of fuel is injected in a cycle, or when the engine is being operated at high load and high speed. At higher engine speeds and loads, the total amount of fuel injected increases and the time available for combustion decreases.

Also, some of the lubricating oil on the cylinder wall is partially burned and contributes to particulate emissions. Finally, a poorly operating or mistimed fuel injection system can substantially increase emissions of particulates.

\section{Diesel Fuel Parameters}

The chosen Diesel fuels with $C N s$ of 40 and 50 were used, respectively. Exhaust gas emissions for each Diesel fuel were estimated at different engine speeds. The main properties of the test fuels used for the theoretical study are given as follow below.

\subsection{Diesel Index Number}

The diesel index $(D I)$ was calculated by using the formula given below:

$$
D I=\frac{\text { API gravity }\left(60^{\circ} \mathrm{F}\right) \times \text { Aniline point }\left({ }^{\circ} \mathrm{F}\right)}{100}
$$

The cetane number $(\mathrm{CN})$ can be calculated as

$$
\begin{gathered}
\text { follows: } C N=\frac{2}{3} D I+ \\
0.068\left[50 \% \text { boiling point }\left({ }^{\circ} \mathrm{F}\right)\right]-22
\end{gathered}
$$

For good quality diesel oil, the aniline point is greater than $70^{\circ} \mathrm{F}$.

High cetane number or high diesel index assists in easy starting at low temperatures, producing low engine pressures and smooth operation as shown in Fig. 1.

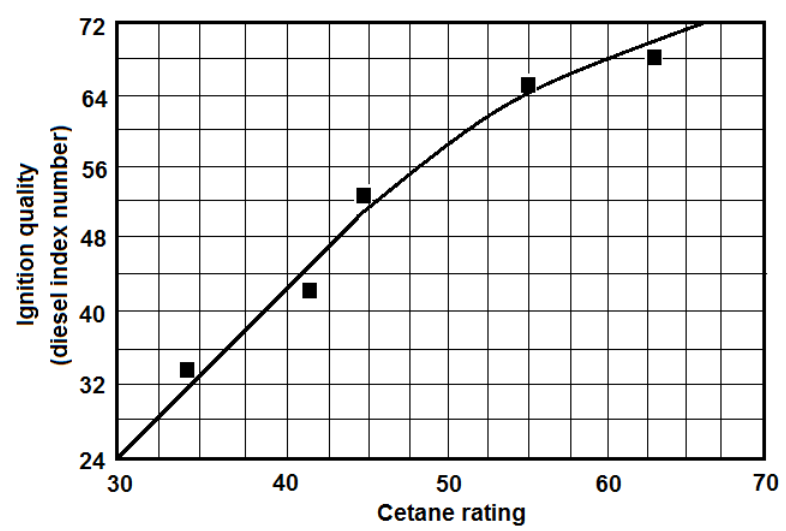

Fig. 1 Relation between diesel index and cetane rating

\subsection{API gravity and specific gravity}

These are expressions of the density or weight of a unit volume of material. The specific gravity is the ratio of the weight of a unit volume of oil to the weight of the same volume of water at a standard temperature of $15{ }^{\circ} \mathrm{C}$. API (American Petroleum Institute) gravity is given by:

$$
A P I=\frac{141.5}{\text { Specific Gravity at } 60^{\circ} \mathrm{F}\left(15^{\circ} \mathrm{C}\right)}-131.5
$$

API gravity is also an index of ignition quality. Higher the API gravity higher is the diesel index for the fuel and lower $b s f c$ as shown in Fig. 2.

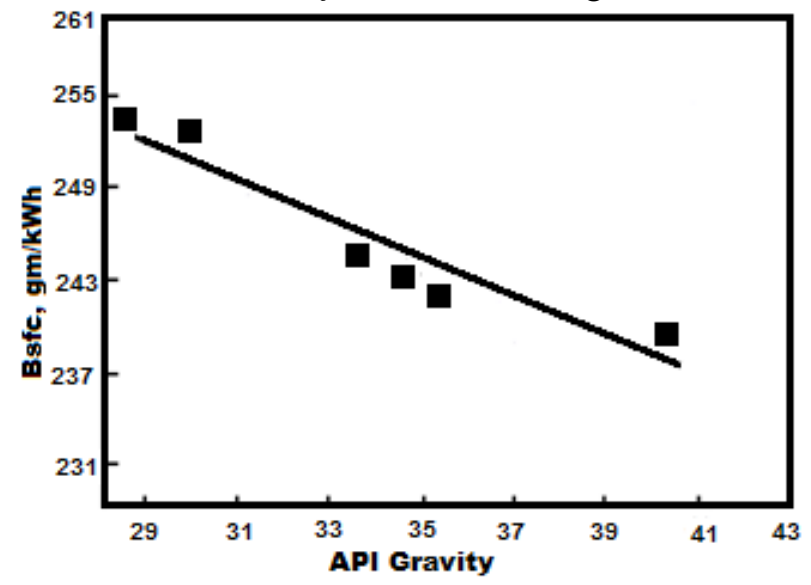

Fig. 2 Effect of fuel API gravity on Engine bsfe $(\mathrm{gm} / \mathrm{kW} . \mathrm{hr})$

\subsection{Ignition quality}

For a diesel fuel smooth spontaneous ignition at relatively low temperature is essential. Ignition delay, the time period between start of injection and start of combustion, has a great influence on the correct optimization of a diesel engine. If it is too long the rate of pressure rise, once it starts, can become so rapid that severe diesel knock and engine damage can occur. If it is too short then there is not sufficient time for complete mixing and smoking can result.

\subsection{Cetane number}

The cetane rating of a diesel fuel is a measure of its ability to autoignition quickly when it is injected into the compressed and heated air in the engine. Though ignition delay is affected by several engine design parameters such as compression ratio, injection rate, injection time, inlet air temperature etc., it is also dependent on hydrocarbon composition of the fuel and to some extent on its volatility characteristic. The cetane number is a numerical measure of the influence the diesel fuel has in determining the ignition delay. Higher the cetane rating of the fuel lesser is the propensity for diesel knock.

The cetane number of a fuel is the percentage by volume of cetane in a mixture of cetane and $\alpha$ methylnapthalene $\left(\boldsymbol{C}_{10} \boldsymbol{H}_{7} \boldsymbol{C H}_{3}\right)$ that has the same performance in the standard test engine as that of the fuel. Cetane $\left(\boldsymbol{C}_{16} \boldsymbol{H}_{34}\right)$ is arbitrarily given a number 100 and originally $\alpha$-methylnapthalen was given a number 0 but now reference is heptamethylnonane which is given the value 15 . 
There is a relationship between octane number $(O N)$ and cetane number $(\mathrm{CN})$ is given by:

$$
C N=\frac{104-O N}{2.75}
$$

It is clear that a good diesel engine fuel is a bad gasoline engine fuel. Diesel fuels have typical cetane rating of 40 to 60 while high octane fuels as gasoline which are difficult to autoignition have cetane number of about 10 to 20 indicating their poor suitability as a diesel fuel.

Cetane number is the most important single fuel property which affects the exhaust emissions, noise and startability of a diesel engine. In general, lower the cetane numbers higher are the hydrocarbon emissions and noise levels. Low cetane fuels increase ignition delay so that start of combustion is nearer to top dead centre. This is similar to retarding of injection timing which is also known to result in higher hydrocarbon levels.

\section{Theoretical Approaches}

The theoretical approaches are used to examine the effect of different fuel cetane numbers $(\mathrm{CNS})$ on reducing the ignition delay and exhaust emissions from diesel engine at certain operating conditions by taking different intake pressures and temperatures with different compression ratios, different fuel types with $C N 40 \& 50$ at different engine speeds.

The diesel engine was run to reach the normal working temperature. Exhaust emissions were carried out first for diesel fuel with a cetane number of 40. Then fuel with cetane numbers of 50 was tested in that order for an injection pressure of 150 bars. All initial conditions were kept constant for each diesel fuel (oil and water temperature, fuel temperature and advance values).

The diesel fuels were used at injection pressure of 150 bars. For these parameters, exhaust emissions were tested at engine speeds from 4500 $\mathrm{min}^{-1}$ to $1000 \mathrm{~min}^{-1}$ at full engine load. All theoretical data were collected and printed out. The results were compared with each other to show the differences and effects of cetane numbers on diesel emissions.

An empirical formula used to estimate the period of ignition delay $\left(\tau_{i}\right)$ in diesel engine is given by [14]:

$$
\begin{gathered}
\tau_{i}(\text { Crank Angle })=(0.36+ \\
\left.0.22 S_{P}\right) \exp \left[E_{A}\left(\frac{1}{R T}-\frac{1}{17190}\right)\left(\frac{21.2}{P-12.4}\right)^{0.63}\right]
\end{gathered}
$$

Where,

$S_{p}=$ mean piston speed $(\mathrm{m} / \mathrm{s})$,

$$
S_{P}=2 \times L \times N
$$

$E_{A}=$ Activation Energy,

$$
E_{A}=\frac{618840}{C N+25}
$$

$R=$ Universal gas constant,

$$
R=8.314 \mathrm{~kJ} / \mathrm{kmol} . \mathrm{K}
$$

$T=$ Temperature at Top Dead Center (TDC),

$$
T_{T D C}=T_{i} \times r_{C}^{n-1}
$$

$T_{i}=$ Intake temperature $(K)$

$r_{C}=$ Compression ratio

$P=$ Pressure at Top Dead Center $(T D C)$,

$$
P_{T D C}=P_{i} \times r_{C}^{n}
$$

$P_{i}=$ Intake pressure $($ bar $)$

$\tau_{i}(m s)=$ Ignition delay in millisecond,

$$
\tau_{i}(m s)=\frac{\tau_{i}(\text { Crank Angle })}{(0.006 \times N)}
$$

\section{Results of the theoretical approaches}

For a diesel fuel smooth spontaneous ignition at relatively low temperature is essential. Ignition delay, the time period between start of injection and start of combustion, has a great influence on the correct optimization of a diesel engine. If it is too long the rate of pressure rise, once it starts, can become so rapid that severe diesel knock and engine damage can occur. If it is too short then there is not sufficient time for complete mixing and smoking can result.

The cetane rating of a diesel fuel is a measure of its ability to autoignition quickly when it is injected into the compressed and heated air in the engine. Though ignition delay is affected by several engine design parameters such as compression ratio, injection rate, injection time, inlet air temperature etc., it is also dependent on hydrocarbon composition of the fuel and to some extent on its volatility characteristic. The cetane number is a numerical measure of the influence the diesel fuel has in determining the ignition delay. Higher the cetane rating of the fuel lesser is the propensity for diesel knock.

The fuel $C N$ is effective to improve the combustion by reducing the ignition delay. It is so clear that at $C N=40$ and at different compression ratios, intake pressures and temperatures the ignition delay decreases as the compression ratios, intake pressures, temperatures and engine speeds are increased. Moreover, the reduction in ignition delay was more remarkable at lower engine speeds and lower compression ratios, as shown in figures 3-5. 


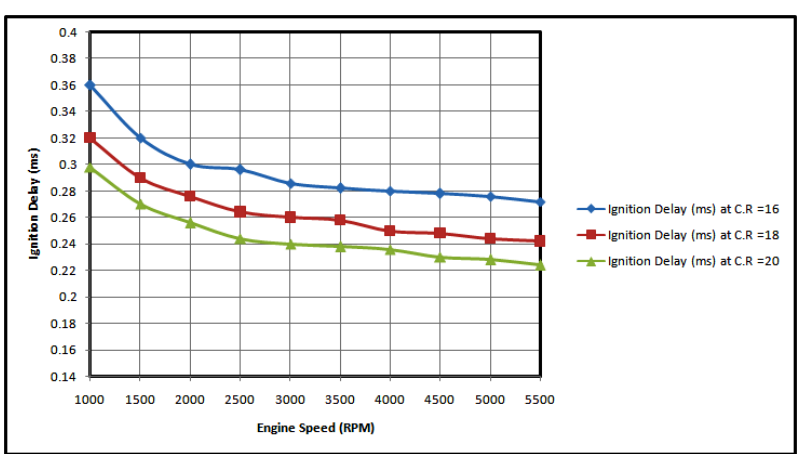

Fig. 3 Variation of Ignition delay against engine speed for $C N=40$ at $P_{i}=1 \mathrm{bar}$ and $T_{i}=15^{\circ} \mathrm{C}$

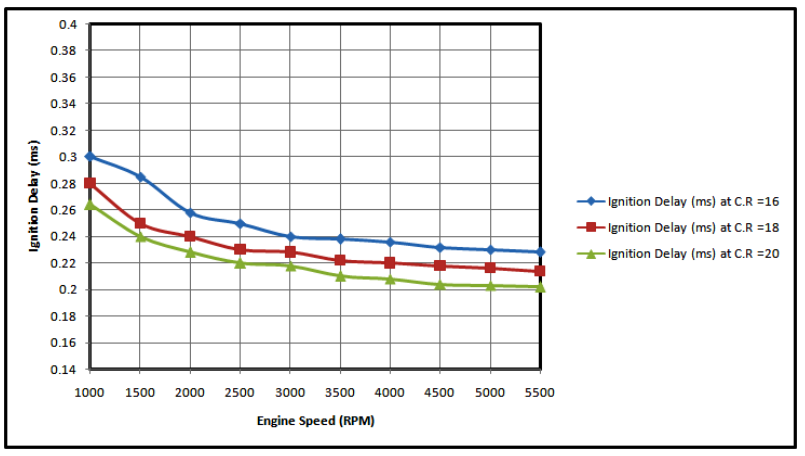

Fig. 4 Variation of Ignition delay against engine speed for $C N=40$ at $P_{i}=1.5 \mathrm{bar}$ and $T_{i}=25^{\circ} \mathrm{C}$

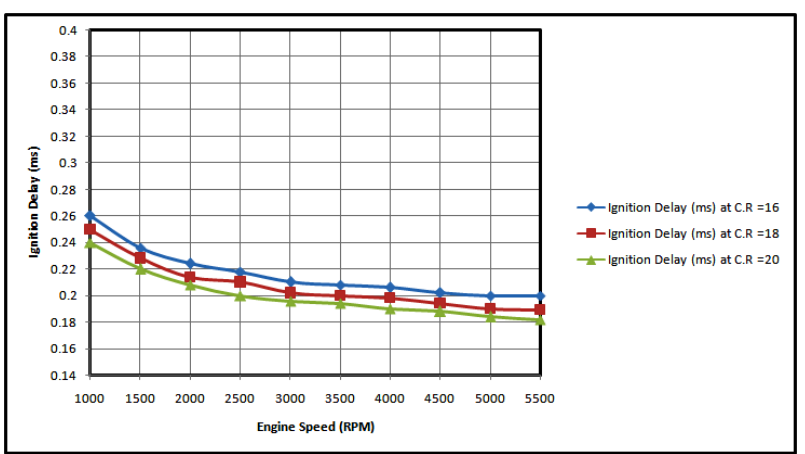

Fig. 5 Ignition delay against engine speed for $C N=40$ at $P_{i}=2.5$ bar and $T_{i}=40^{\circ} \mathrm{C}$

As shown in figures 6-8, at different operating conditions, the ignition delay decreased as the cetane number increased to $C N=50$ compared to the same cases at $C N=40$.

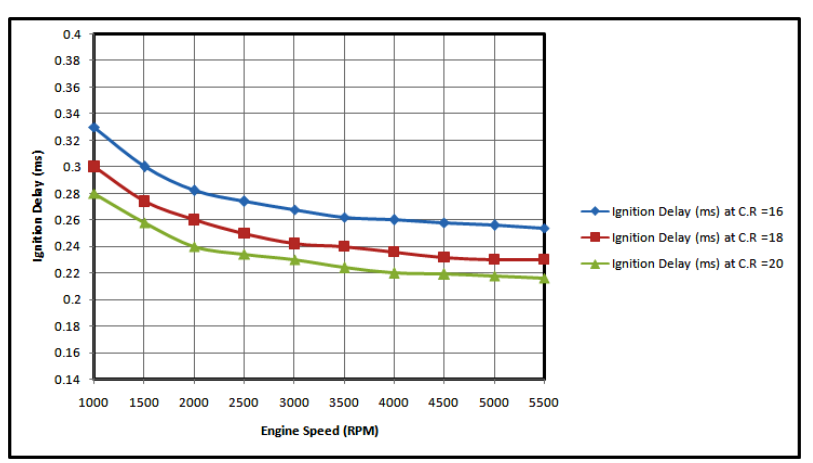

Fig. 6 Ignition delay against engine speed for $C N=50$ at $P_{i}=1 \mathrm{bar}$ and $T_{i}=15^{\circ} \mathrm{C}$

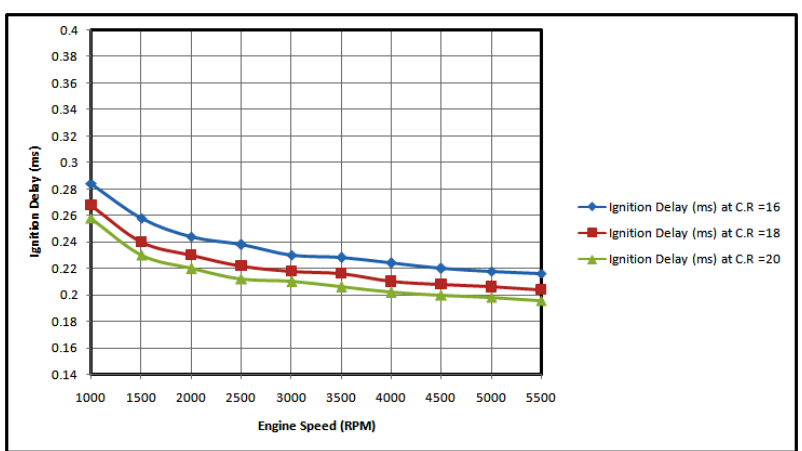

Fig. 7 Ignition delay against engine speed for $C N=50$ at $P_{i}=1.5 \mathrm{bar}$ and $T_{i}=25^{\circ} \mathrm{C}$

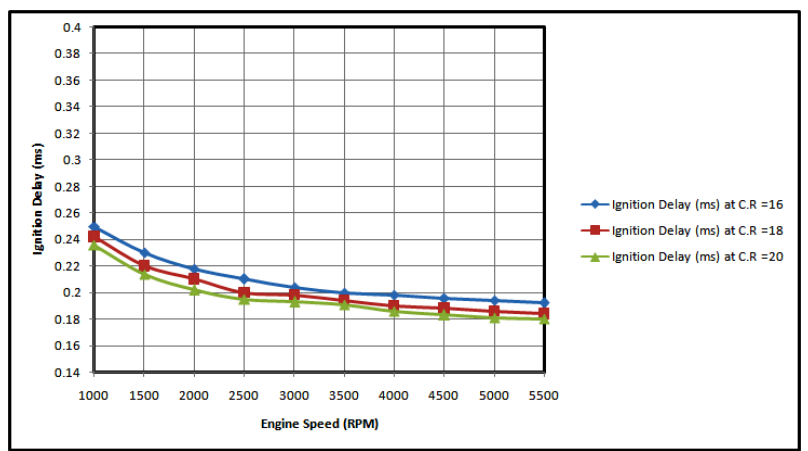

Fig. 8 Ignition delay against engine speed for $C N=50$ at $P_{i}=2.5$ bar and $T_{i}=40^{\circ} \mathrm{C}$

The fuel $C N$ is effective to improve the combustion process of diesel engine. In the case of increasing $C N$ from 40 to 50, ignition delay is reduced so that combustion efficiency is improved as shown in Fig. 9.

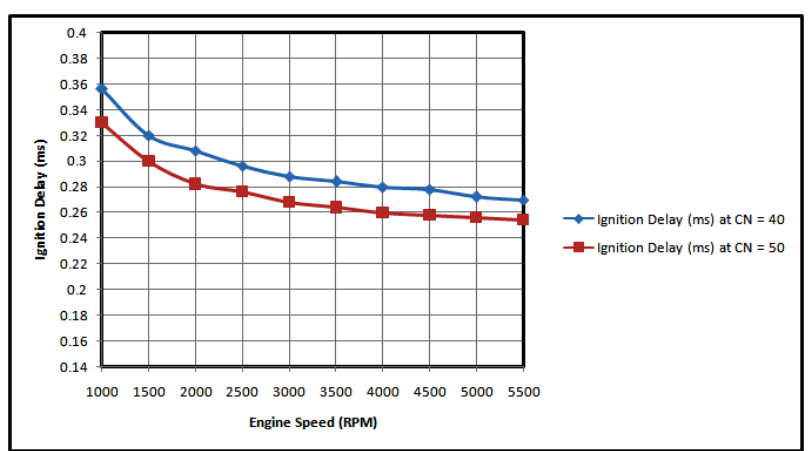

Fig. 9 Ignition delay against engine speed for $C N=40$ and $C N=50$ at $P_{i}=1 \mathrm{bar}$ and

$$
T_{i}=15^{\circ} \mathrm{C}
$$

The variation in NOx emissions with cetane number is shown in Fig. 10 keeping the injection pressure constant at 150 bars. It can be seen from the graphs that NOx emissions decrease when the fuel cetane numbers are increased. The lowest value of $N O x$ is obtained for $1000 \mathrm{~min}^{-1}$ engine speed. The tendency to reduce $N O x$ can be observed for all speeds, 1000,3000 and $4500 \mathrm{~min}^{-1}$, by increasing the $C N$. This can be attributed to the fact that increasing $C N$ ensures shorter ignition delay and, hence, better combustion. 


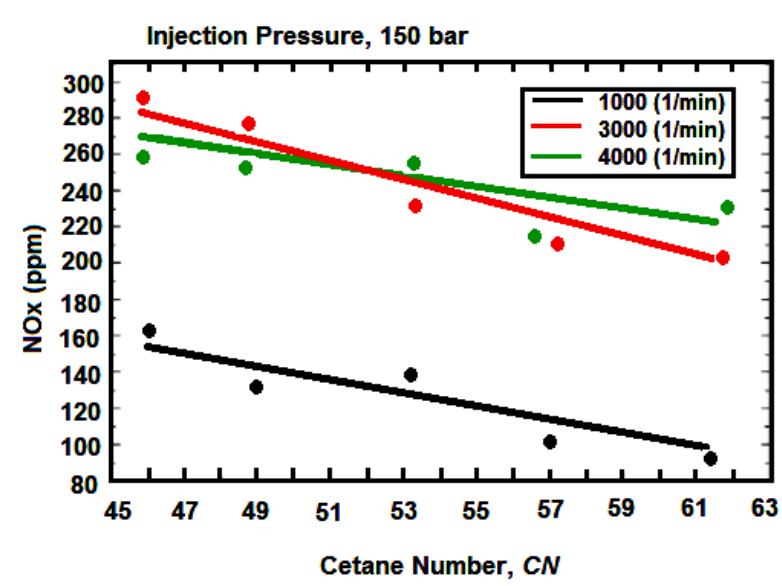

Fig. 10 Variations of Nitrogen Oxide $\left(\mathrm{NO}_{\mathrm{x}}\right)$ by CN

The variation in $\mathrm{SO}_{2}$ emissions with cetane number is shown in Fig. 11 keeping the injection pressure constant at 150 bars. It can be seen from the graphs that $\mathrm{SO}_{2}$ emissions decrease when the fuel cetane numbers are increased. The lowest value of $\mathrm{SO}_{2}$ is obtained for $1000 \mathrm{~min}^{-1}$ engine speed. The tendency to reduce $\mathrm{SO}_{2}$ can be observed for all speeds, 1000, 3000 and 4500 $\mathrm{min}^{-1}$, by increasing the $C N$. This can be attributed to the fact that increasing $C N$ ensures shorter ignition delay and, hence, better combustion.

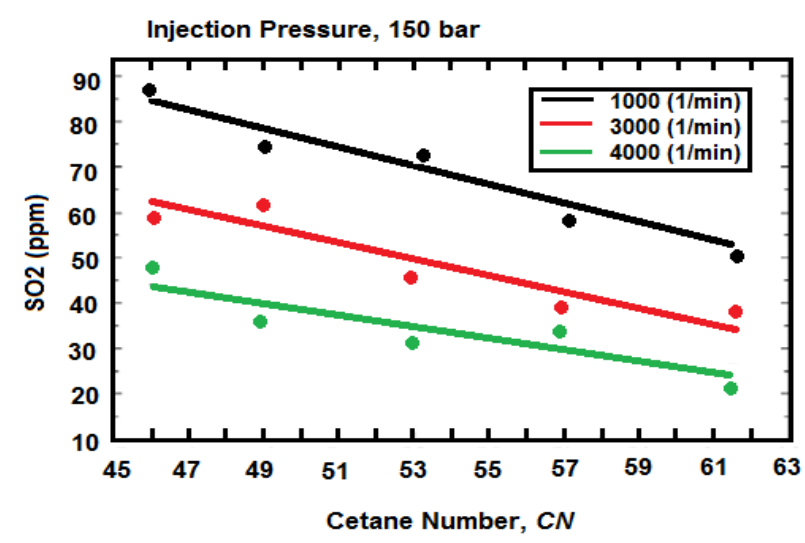

Fig. 11 Variations of sulphur dioxide $\left(\mathrm{SO}_{2}\right)$ by $C N$

A reduction in $C O$ emission can be seen at lower engine speeds when the cetane number is increased from 40 to 50 shown in Fig. 12. Emissions of $C O$ are therefore greatly dependent on the air-fuel ratio relative to the stoichiometric proportions. As diesel engines operate with an overall lean mixture, their $\mathrm{CO}$ emissions are normally well below legislated limits and of not much concern. Any $C O$ from diesel engine is due to incomplete mixing, with combustion taking place in locally rich conditions.

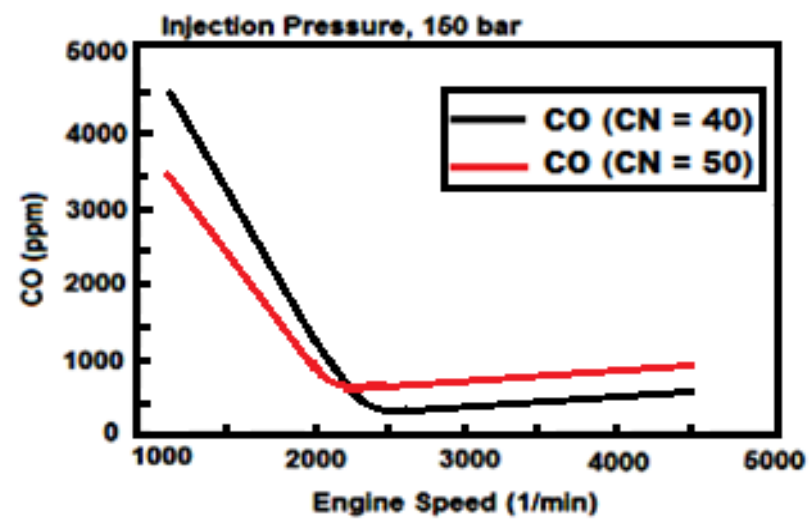

Fig. 12 Variations of Carbon Monoxide $(\mathrm{CO})$ by $C N$

The effect of fuel $C N$ on the engine performance is shown in Fig. 13. It is clearly seen that engine torque and power are improved when the fuel $C N$ is increased. These changes can be observed more clearly for the $C N s$ between 40 and 50 .

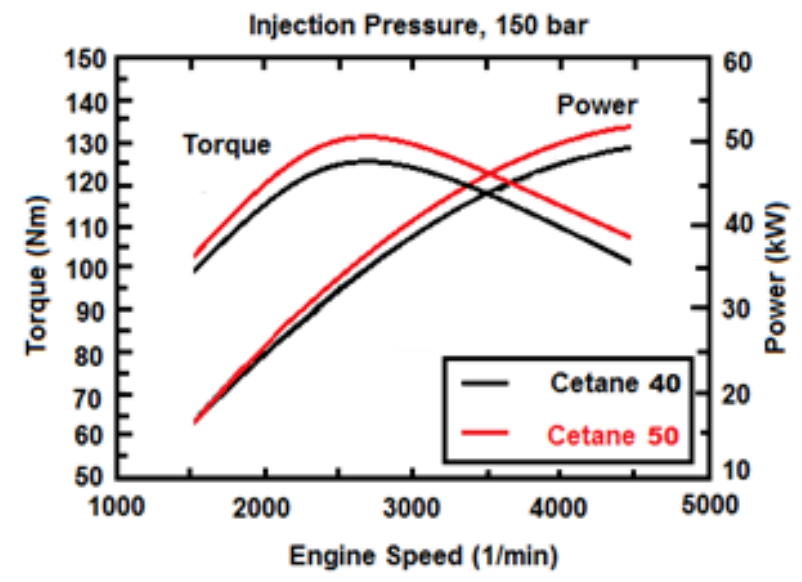

Fig. 13 Effect of $\mathrm{CN}$ on the engine performance

\section{Conclusions}

In this present study a theoretical model is used to examine the effect of different fuel cetane numbers $(C N s)$ on ignition delay period, exhaust emissions and performance of diesel engine. The results showed that the ignition delay is decreased as fuel cetane number, engine speed, intake pressures and temperatures and compression ratios are increased. Also, by increasing $C N$, ignition delay is reduced so that combustion efficiency is improved. The $\mathrm{NOx}$ and $\mathrm{SO}_{2}$ emissions are reduced when the fuel $\mathrm{CN}$ is increased. The $C O$ emissions are reduced when the fuel $\mathrm{CN}$ is increased at lower engine speed. Finally, engine torque and power are improved when the fuel $C N$ is increased. 


\section{References:}

[1] J. B. Heywood, Internal Combustion Engine Fundamentals, McGraw-Hill, 1988.

[2] P. Ghosh and S. B. Jaffe, "Detailed composition-based model for predicting the cetane number of diesel fuels," Industrial and Engineering Chemistry Research, vol. 45, no. 1, pp. 346-351, 2006.

[3] G. K. Lilik and A. L. Boehman, "Advanced diesel combustion of a high cetane number fuel with low hydrocarbon and carbon monoxide emissions," Energy \& Fuels, vol. 25, no. 4, pp. 1444-1456, 2011.

[4] Kent B, Terry L, Ullman L, Robert LM., Effects of cetane number, cetane improver, aromatics, and oxygenates on heavy-duty Diesel engine emissions. SAE Paper No. 941020, 1994.

[5] Terry L, Kent B, Robert LM., Effects of fuel aromatics, cetane number, and cetane improver on emissions from prototype heavy-duty Diesel engine. SAE Paper No. 902171, 1990.

[6] Kent B, Terry L, Ullman L, Robert LM. Effects of cetane number, aromatics and oxygenates on emissions from heavy-duty Diesel engine with exhaust catalyst. SAE Paper No. 950250, 1995.

[7] McMillan ML, Halsall R. Fuels effects on combustion and emissions in a direct injection diesel engine. SAE Paper No. 881650, 1988.

[9] Clark RH, Cowley LT, Lange WW., Fuel quality effects on particulate matter emissions from light and heavy duty Diesel engines. SAE Paper No. 942022, 1994.

[10] Ullman TL., Investigation of the effects of fuel composition on heavy-duty diesel engine emissions. SAE Paper No. 892072, 1989.
[11] X. C. Lü, J. G. Yang, W. G. Zhang, and Z. Huang, "Improving the combustion and emissions of direct injection compression ignition engines using oxygenated fuel additives combined with a cetane number improver," Energy \& Fuels, vol. 19, no. 5, pp. 1879-1888, 2005.

[12] Kitano, K., Nishiumi, R., Tsukasaki, T., Tanaka, T., Morinaga, M., 'Effects of fuel properties on premixed charge compression ignition combustion in a direct injection diesel engine.' SAE paper 2003-01-1815, 2003

[13] Kusaka, J., Suzuki, K., Miyoshi, A., Daisho, Y., 'Study on combustion in light duty diesel engines - the effect of fuel properties for PCI (premixed compression ignition) combustion.' SAE Japan paper 20045751, 2004

[14] H. O. Hardenberg, F. W. Hase. An Empirical formula for computing the pressure rise delay of a fuel from its cetane number and from the relevant parameters of direct injection diesel engines. SAE Technical Paper 790493, SAE, 1979.

\section{Creative Commons Attribution}

License 4.0 (Attribution 4.0

International , CC BY 4.0)

This article is published under the terms of the Creative Commons Attribution License 4.0 https://creativecommons.org/licenses/by/4.0/deed.e $\underline{\text { n US }}$ 